\title{
Device Explosion
}

National Cancer Institute

\section{Source}

National Cancer Institute. Device Explosion. NCI Thesaurus. Code C133505.

Problem with the device associated with the violent bursting due to the sudden expansion of air, gas or fluid. 